\title{
ENROLLEE MIX, TREATMENT INTENSITY, AND COST IN COMPETING INDEMNITY AND HMO PLANS
}

\author{
Daniel Altman \\ David M. Cutler \\ Richard J. Zeckhauser \\ Working Paper 7832 \\ http://www.nber.org/papers/w7832
NATIONAL BUREAU OF ECONOMIC RESEARCH 1050 Massachusetts Avenue
Cambridge, MA 02138

August 2000

The authors thank Don Westwater (Massachusetts Group Insurance Commission), Dan Robertson (formerly of the MEDSTAT Group), and Srikanth Kadiyala (NBER) for helpful discussions and the National Institutes on Aging and Alfred P. Sloan Foundation for financial support. The data used in this paper are proprietary. The views expressed herein are those of the authors and not necessarily those of the National Bureau of Economic Research.

(C) 2000 by Daniel Altman, David M. Cutler, and Richard J. Zeckhauser. All rights reserved. Short sections of text, not to exceed two paragraphs, may be quoted without explicit permission provided that full credit, including (C) notice, is given to the source. 
Enrollee Mix, Treatment Intensity, and Cost in Competing Indemnity and HMO Plans

Daniel Altman, David M. Cutler, and Richard J. Zeckhauser

NBER Working Paper No. 7832

August 2000

JEL No. I1

\begin{abstract}
We examine why managed care plans are less expensive than traditional indemnity insurance plans. Our database consists of the insurance experiences of over 200,000 state and local employees in Massachusetts and their families, who are insured in a single pool. Within this group, average HMO costs are 40 percent below those of the indemnity plan. We evaluate cost differences for 8 conditions representing over 10 percent of total health expenditures. They are: heart attacks, cancers (breast, cervical, colon, prostate), diabetes (type I and II), and live births. For each condition, we identify the portions of the cost differential arising from differences in treatment intensity, enrollee mix, and prices paid for the same treatment. Surprisingly, treatment intensity differs hardly at all between the HMOs and the indemnity plan. That is, relative to their fee-for-service competitor, HMOs do not curb the use of expensive treatments. Across the 8 conditions, roughly half of the HMO cost savings is due to the lower incidence of the diseases in the HMOs. Virtually all of the remaining savings come because HMOs pay lower prices for the same treatment.
\end{abstract}

Daniel Altman

The Economist Newspaper Ltd.

25 St. James's Street

London SW1A 1HG

United Kingdom

danielaltman@economist.com

Richard Zeckhauser

Kennedy School of Government

Harvard University

Cambridge, MA 02138

richard_zeckhauser@harvard.edu

and NBER
David M. Cutler

Department of Economics

Harvard University

Cambridge, MA 02138

dcutler@harvard.edu

and NBER 
Indemnity insurance plans frequently cost far more than their managed care competitors. A generous indemnity insurance plan, for example, might cost over $\$ 4,000$ per covered life annually, while a plan offered by a tightly managed health maintenance organization (HMO) may cost only half as much.

Effective policy-making requires that the sources of such significant cost differences be understood. If managed care plans are substantially cheaper than indemnity plans yet achieve equivalent medical outcomes, policies should induce more people to join those plans (for example, by converting insurance options into a fixeddollar-contribution voucher system). By contrast, if managed care plans achieve their savings solely by selecting better risks, such encouragement would not be warranted.

This paper examines why managed care plans are less expensive than traditional indemnity plans. It focuses on medical care costs and treatment intensity for the insurance plans offered to state and local employees in Massachusetts. The Group Insurance Commission of Massachusetts (GIC) is responsible for providing insurance to these individuals and their families. It does so by contracting with an indemnity plan, 10 HMOs, and a preferred provider organization (PPO). We group the HMOs together for this analysis and examine the cost difference between the indemnity plan and the HMOs as a whole.

The GIC is particularly valuable for study because of its large insurance poolmore than 215,000 covered lives under age 65 - and the wide differences in costs across plans. In fiscal year 1998, for example, the individual premium for the indemnity policy was 77 percent greater than the individual premium for the most expensive HMO. Beyond its academic interest, this large premium differential concerns the GIC 
commissioners. They are interested in understanding why, even after tough negotiations, the plans charge such different amounts. ${ }^{1}$

We divide spending differences into three possible sources. The first source is differences in enrollee mix across plans. There are two types of differences in mix. HMOs may be cheaper because of incidence mix (the incidence of costly medical conditions is lower in those plans) or because of within-condition mix (HMO enrollees have less severe cases of disease than indemnity plan members).

Differences in both types of mix may result from adverse selection. Evidence on adverse selection is plentiful (see Cutler and Zeckhauser, 1999, for a review). Studies uniformly show that HMOs enroll younger, healthier members than indemnity insurance plans (e.g., Scitovsky, McCall and Benham, 1978; Jackson-Beeck and Kleinman, 1983; Ellis, 1989; Langwell and Hadley, 1989). Given a choice, healthier people are more likely to choose managed care plans than are less healthy people (Cutler and Zeckhauser, 1998). In addition, non-movers may contribute significantly more to indemnity plan costs than to the HMOs' costs as they age (Altman, Cutler and Zeckhauser, 1998).

The second potential source of cost differences is differences in treatment intensity. The indemnity plan may be more expensive because it provides more intensive procedures for patients with similar diagnoses, perhaps because its benefit structure is more generous. Treatment intensity is not necessarily greater in indemnity plans; HMOs are claimed by some to be more intensive than indemnity plans for services such as preventive care, in an effort to stave off high-cost medical conditions.

\footnotetext{
${ }^{1}$ Zeckhauser is a GIC commissioner.
} 
The third potential source is differentials in prices. HMOs may be cheaper because they pay lower prices for the same services than does the indemnity plan. Price differences might result from bargaining: HMOs enjoy bargaining leverage because unlike indemnity plans - they have the ability to direct large groups of patients to providers. If the group elasticity of demand is greater than the individual elasticity of demand, HMOs might use the greater demand elasticity to extract lower prices. Price differences could also stem from a more efficient production process, for instance in billing and administering purchases of medical services.

There could also be interactive relationships among these variables. For example, prices paid by the two plans might be somewhat closer together for conditions where the indemnity plan has relatively higher incidence. This would produce a negative interaction term between prices and mix. In this analysis, we parcel out direct (noninteractive) effects but discuss interaction effects as well.

Differentiating between enrollee mix, treatment intensity, and price effects requires detailed data on incidence, treatments received, and prices paid for a variety of medical conditions. Even with complete data, however, one difficulty remains in any attempt to measure sources of differentials in cost: selection into treatment. Imagine that rates of respiratory infection are common across plans, but that affected people in HMOs are less likely to see a doctor and only visit when they are very sick. Naïve analysis of medical care utilization would suggest that HMOs have healthier enrollees than indemnity plans (fewer treatments for respiratory infection) but treat them more aggressively (more intense treatment when they do visit a doctor). Neither of these inferences is valid, given the underlying selection behavior. 
To steer clear of selection issues, we examine conditions where treatment of some form is extremely likely. We focus on eight common and easily identifiable medical conditions: heart attacks; births; cancers of the breast, colon, cervix, and prostate; and type I (juvenile-onset) and type II (adult-onset) diabetes. These conditions are a mix of acute conditions and chronic conditions with major cost implications. ${ }^{2}$ Together, these eight conditions account for over 13 percent of total medical spending in the GIC's health plans.

Our results show that differences in costs between the indemnity plan and HMOs result predominantly from differences in incidence and price. Seven of our eight conditions have significantly higher incidence rates in the indemnity plan. For these conditions, differences in the incidence of disease account for about 47 percent of cost differences on average. An additional 45 percent of cost differences result from differences in the price of the same services. Differences in severity of disease and treatment intensity each account for four or five percent of cost differences.

Our work is related to several papers in the literature. Some studies show that treatment differences are substantial across plans. Miller and Luft $(1994,1997)$, for instance, document that HMOs have both fewer hospitalizations and shorter hospital stays than indemnity plans. This situation produces total savings generally estimated at about 10 percent of costs (net of some increase in outpatient spending). Eichner, McClellan, and Wise (1999), using a sample of patient costs compiled from several private employers, examine cost differences across indemnity plans in different firms. They find

\footnotetext{
${ }^{2}$ We omit lung cancer because it is most common among elderly insurees, who are not covered in this research because they hold a combination of Medicare and private insurance.
} 
that demographic mix and treatment costs are largely responsible for cost differences in these plans. However, they do not separate the cost differences into treatment intensity and price. Cutler, McClellan and Newhouse (2000) examine treatment intensity and price differences in treating heart attack patients in fee-for-service and managed care plans, but do not focus on differences in the mix of enrollees. To the best of our knowledge, ours is the only paper that decomposes cost differences across plans into effects attributable to mix, intensity, and prices for a wide range of conditions. The most difficult ingredient in such an analysis is detailed price data. Data on prices paid are hard to come by, given the competitive implications of making such information public and the secrecy with which it is typically held.

This paper is structured as follows. The first section describes the methods that we use to parcel out cost differences across plans. The second section outlines the data, and the third section presents the cost decomposition. The last section concludes.

\section{Methodology}

Individuals who are sick may have one of a variety of conditions. We index conditions by $j$. The set of conditions that people may contract is very large; in our empirical analysis, we address eight that are well-defined and relatively common. Within each condition, we index treatments $t$ by $k$, where $k$ runs from 1 to $K_{j}$. We think of these treatments as treatment paths - major ways of approaching a given disease - rather than a completely specified set of procedures. For example, treatment paths for breast cancer are surgery, radioactive oncology/chemotherapy, or a combination of the two. This 
formulation serves both theoretical and practical purposes. Theoretically, patients care more strongly about treatment paths than about the myriad of specific items within a path. Practically, many of the plans do not report all of the specific services provided, since payment is often made on the basis of the treatment path itself. We divide patients into demographic categories indicated $d_{i}$, where $i$ runs from 1 to $N$. Finally, plans are indexed by $P$, where $P=I$ for the indemnity plan and $P=H$ for the HMOs.

Denote the incidence of condition $j$ among people in plan $P$ as $q_{j}^{P}$. The fraction of people who are in plan $P$, suffering condition $j$, and in demographic group $i$ is $d_{i j}^{P}$. Average treatment fractions and reimbursement dollars for those individuals are $t_{i j k}^{P}$ and $r_{i j k}^{P}$. Average per capita costs in plan $P$ from a condition $j$ are therefore equal to:

$$
x_{j}^{P}=q_{j}^{P} \cdot \sum_{i=1}^{N}\left(d_{i j}^{P} \cdot \sum_{k=1}^{K} t_{i j k}^{P} \cdot r_{i j k}^{P}\right) .
$$

The difference in per capita average costs across plans for treatment of a given condition $j, \Delta x_{j}^{I-H}$, can be decomposed into overall incidence, within-condition demographic mix, treatment, and price effects. Taking the indemnity plan as the base, this difference is approximately: ${ }^{3}$

$$
\Delta x_{j}^{I-H} \cong\left\{\left(q_{j}^{I}-q_{j}^{H}\right) \cdot \sum_{i=1}^{N}\left[d_{i j}^{I} \cdot\left(\sum_{k=1}^{K} t_{i j k}^{I} \cdot r_{i j k}^{I}\right)\right]\right\}+q_{j}^{I}\left\{\begin{array}{l}
\sum_{i=1}^{N}\left[\left(d_{i j}^{I}-d_{i j}^{H}\right) \cdot\left(\sum_{k=1}^{K} t_{i j k}^{I} \cdot r_{i j k}^{I}\right)\right]+ \\
\sum_{i=1}^{N}\left[d_{i j}^{I} \cdot\left(\sum_{k=1}^{K}\left(t_{i j k}^{I}-t_{i j k}^{H}\right) \cdot r_{i j k}^{I}\right)\right]+ \\
\sum_{i=1}^{N}\left[d_{i j}^{I} \cdot\left(\sum_{k=1}^{K} t_{i j k}^{I} \cdot\left(r_{i j k}^{I}-r_{i j k}^{H}\right)\right)\right]
\end{array}\right\}
$$

\footnotetext{
${ }^{3}$ Our results are similar if we take the HMOs as the base.
} 
The first term, $\left(q_{j}^{I}-q_{j}^{H}\right) \cdot \sum_{i=1}^{N}\left[d_{i j}^{I} \cdot\left(\sum_{k=1}^{K} t_{i j k}^{I} \cdot r_{i j k}^{I}\right)\right]$, represents the per capita cost difference resulting from differences in the overall incidence of condition $j$ between plans. The top term in the second set of brackets, $q_{j}^{I} \sum_{i=1}^{N}\left[\left(d_{i j}^{I}-d_{i j}^{H}\right) \cdot\left(\sum_{k=1}^{K} t_{i j k}^{I} \cdot r_{i j k}^{I}\right)\right]$, is the cost difference from differences in the demographic mix of sufferers of the condition; the middle term, $q_{j}^{I} \sum_{i=1}^{N}\left[d_{i j}^{I} \cdot\left(\sum_{k=1}^{K}\left(t_{i j k}^{I}-t_{i j k}^{H}\right) \cdot r_{i j k}^{I}\right)\right]$, is the cost difference from treatments conditional on demographics; and the bottom term, $q_{j}^{I} \sum_{i=1}^{N}\left[d_{i j}^{I} \cdot\left(\sum_{k=1}^{K} t_{i j k}^{I} \cdot\left(r_{i j k}^{I}-r_{i j k}^{H}\right)\right)\right]$, is the difference from prices conditional on demographics and treatments.

Equation (2) is only approximate as it omits the second-, third-, and fourth-order covariance terms. Our goal is to estimate the components of equation (2). The mathematical appendix supplies a hypothetical, easy-to-follow example of our calculations.

\section{Data}

Our data are from the Group Insurance Commission (GIC) of Massachusetts, the organization that insures state and some local employees. In FY95, there were 215,287 enrollees in the under- 65 portion of the GIC's pool. These enrollees were divided into three plan types: 67,789 in an indemnity plan, 122,421 in 10 HMOs, and 25,077 in a PPO. The PPO was new in FY94, and is relatively small. We therefore omitted it from this analysis (see Altman, Cutler and Zeckhauser (1998) for further discussion). 
The indemnity plan offers the most generous coverage and carries the highest premium. ${ }^{4}$ Table 1 shows average costs in the indemnity plan and the HMOs for fiscal year 1995. The HMOs have approximately 35 percent lower premiums than the indemnity plan. They are also more restrictive, covering treatment only within their provider networks (except for emergency care). In exchange, they charge lower copayments for in-network services.

Our data, compiled and maintained for the GIC by the MEDSTAT Group, describe plan enrollees' use of inpatient and outpatient hospital services as well as their claims for prescription drugs. For each medical visit, a record gives the primary and secondary diagnoses, the principal procedure administered, and the relevant payment information. This enables us to construct detailed histories of each enrollee's use of a variety of health care resources. Eligibility information is available for essentially all the patients. ${ }^{5}$

Reimbursement information for treatments rendered is based on actual payments rather than "list prices." Our methods cannot account for the effects of any differences in reporting practices between the HMOs and the indemnity plan. For example, bulk purchases of medical treatment from providers by HMOs could lead to peculiar

\footnotetext{
${ }^{4}$ The employer, i.e., the state or a local government unit, covers 85 percent of the cost differential between plans. This significantly reduces the incentive for the insured to choose an HMO over the more expensive indemnity plan. Moreover, as opposed to employers who offer constant subsidies across plans (e.g., Harvard University) this situation creates a much smaller incentive for the insured to move between plans in an effort to save money. Selection within the GIC is therefore more likely due to services offered, perceptions about services offered, and hysteresis (Cutler and Zeckhauser, 1998).

${ }^{5}$ Same-sex twins present a problem, as they have almost always have the same date of birth, sex, and relationship to the principal enrollee. Our methods may collapse some same-sex twins into one enrollee. Tabulations using eligibility files indicate that very few such cases exist in the data.
} 
disaggregations of payments at the patient level. However, we have no reason to suspect any systematic biases. ${ }^{6}$

We focus on eight conditions where treatment of some form is necessary or highly likely in order to minimize selection into treatment. For research purposes, these conditions have the advantage of being very expensive. In total, they account for 15 percent of the indemnity plan's costs and 11 percent of the HMOs' costs. The conditions are listed in Table 2 along with their respective treatment options and the universes of patients within which we study them. The universes are chosen to exclude demographic groups where incidence is extremely low or zero.

For acute myocardial infarction (AMI, or heart attack in common parlance) we follow Cutler et al. $(1998,2000)$ and group patients into four major treatment categories. Coronary artery bypass graft surgery $(\mathrm{CABG})$ is the most radical procedure; the patient's artery is cut and augmented with an unblocked section of artery from elsewhere in the body, usually a leg. Percutaneous transluminal coronary angioplasty (PTCA) inflates a balloon inside the patient's artery in an attempt to clear blockages; for less serious cases, it is an alternative to $\mathrm{CABG}$, less invasive and sometimes cheaper. ${ }^{7}$ Some patients receive cardiac catheterization, a diagnostic procedure in which a dye is circulated through the patients' arteries to determine the location and magnitude of blockages, but there is no further invasive procedure. Finally, some patients are treated without any of the intensive procedures (designated the "null" treatment path).

\footnotetext{
${ }^{6}$ We are grateful to Don Westwater of the GIC for discussing this issue with us.

${ }^{7}$ We find only a handful of cases where a PTCA, presumably unsuccessful, is followed by a CABG; these cases are categorized as CABG patients.
} 
For births, we differentiate between normal and caesarian-section deliveries. We consider only pregnancies that result in live births, as these are the simplest to identify in the GIC eligibility files. Twins are treated as one birth event.

We consider cancers affecting four different parts of the body: the breast, cervix, colon and prostate. We identify cancer patients as those whose records contain a diagnosis of one of four major cancers matched with either surgery or radioactive oncology and/or chemotherapy (RO/C) treatment. ${ }^{8}$ For the cancers, the three different treatment paths are surgery, $\mathrm{RO} / \mathrm{C}$, and a combination of the first two treatments. A rough ranking of the paths' intensity would position $\mathrm{RO} / \mathrm{C}$ alone as the least intense, then surgery, then a combination of both as the most intensive. We also track inpatient and outpatient visits involving diagnostic radiology and patient management. ${ }^{9}$ The vast majority of cancer sufferers in either plan undergo surgery, and thus follow either the first or the third treatment path.

The last column of Table 2 describes our conventions for identifying conditionrelated claims. We follow AMI patients for 90 days starting from the first admission for a heart attack. For births, we include nine months of spending prior to the birth, and spending for mother and child for seven days after the birth. Cancers elicit a mix of acute and chronic care. They may result in a high initial expenditure followed by monitoring

\footnotetext{
${ }^{8}$ We do not include a null path for cancer treatment, since records may contain cancer diagnoses for procedures designed only to detect (and not to treat) cancers. Even if cancer is not detected, patients may still receive a cancer diagnosis. For example, mammograms performed to detect breast cancer are usually accompanied by a breat cancer diagnosis though the results of the tests could be negative.

${ }^{9}$ Patient management includes office visits, inpatient observation, emergency room visits not resulting in procedures, counseling, etc. Note also that the surgery path corresponds to any cancer-related surgery during the six-month episode (to allow for metastasization, the spread of cancer through the body).
} 
costs, with considerable extra costs should there be a recurrence. We sum cancer patients' expenditures for six months after the initial diagnosis of a tumor. ${ }^{10}$

To analyze diabetes, a chronic condition, we use a longer time horizon. We code individuals as diabetics if they have two or more diabetes-related diagnoses. Once we have identified a diabetic, we collect all of his or her medical costs for the entire two-year period of our sample. ${ }^{11}$ A multitude of symptoms, side effects, costs and complications can accompany diabetes, so we do not focus on any specific treatments or associated diseases.

\section{Results}

In this section, we decompose differences in costs across plans into mix effects, treatment effects, and price effects.

\section{A. Mix Effects}

Mix effects are divided into two types, incidence and within-condition mix. The incidence effect is the effect of differing overall rates of disease in the two plans. The within-condition mix is the effect of differing demographics conditional on suffering the condition.

\footnotetext{
${ }^{10}$ Since we do not have access to insurees' medical histories before FY94, an "initial" diagnosis of cancer could be part of an ongoing treatment process.
} 


\section{Incidence}

Table 3 presents data on the demographic characteristics of enrollees in the different plans. The table shows the share of each plan's total enrollment in different age and sex groups. The indemnity plan has much older members. One-third of indemnity plan enrollees under age 65 are above age 50, compared with fewer than 15 percent of HMO enrollees. Children account for nearly twice as large a share of enrollees in the HMOs as in the indemnity plan. The mix of men and women is roughly similar across plans.

These age differences translate into substantially different incidence rates, particularly for AMI and cancer. The first columns of Table 4 show the incidence rates for the different conditions. For every condition except cervical cancer, incidence rates are statistically significantly higher in the indemnity plan than in the HMOs. The ratio of incidence rates in the indemnity plan compared to the HMOs is generally two or three to one.

Differences in incidence rates may result from demographic differences across plans as well as differences within demographic groups- healthy 50-year-olds may be more likely to enroll in an HMO than sick 50-year-olds, for example. The second columns of Table 4 examine this by adjusting incidence rates for differences in demographics across plans (five-year age and sex groups). Even within demographic groups, mix differences are important. The intra-group incidence rate for all of the conditions except cervical cancer is about 50 percent higher in the indemnity plan than in the HMOs.

\footnotetext{
${ }^{11}$ This implicitly assumes that the diabetes was contracted before our sample period begins.
} 
The differences in incidence rates between the plans result in large gaps in per capita costs. Table 5 shows that incidence rates for each of these conditions individually are responsible for roughly three percent of the difference in total per capita plan costs over two years, at least for the conditions we study. The first two columns report per capita costs from all conditions and for these specific conditions for patients in the indemnity plan and HMOs. The third column shows what per capita costs would have been for these specific conditions in the indemnity plan if the incidence rates had been the same as in the HMOs. The last column shows what percentage of the difference in per capita plan costs for all conditions is accounted for by the incidence rate for the single condition in question. The estimates range from 0 to 5 percent.

Table 6 show the magnitude of these effects using another metric - how much of differing treatment costs for each disease they explain. The first column of the table shows the difference in average reimbursement between the indemnity plan and the HMOs, on a per capita basis. ${ }^{12}$ Averaged across the eight conditions, per enrollee reimbursement is higher in the indemnity plan by $\$ 107$. The next column shows the effect of differing incidence rates. The higher incidence rate in the indemnity plan in comparison to the HMOs explains 47 percent of cost differences on average.

\section{Within-Condition Mix}

The second part of mix effects is the fact that the demographic mix of people with the disease may differ across plans. The importance of within-condition demographic

\footnotetext{
${ }^{12}$ Here "per capita" covers the groups of enrollees we follow to track the incidence of the eight conditions as listed in Table 2 (e.g., men aged 30-64 for prostate cancer).
} 
differences for the costs of our eight conditions is shown in Table 6. As the third column of Table 6 shows, demographic differences in the within-condition mix of sufferers explain about four percent of these cost differences. Within-condition mix is not a large contributor to differing costs by plan.

\section{B. Treatment Intensity Effects}

To see how treatments can affect cost differences between plans, we compare the share of each plan's patients receiving more serious (or costly) treatments for the same diagnoses. Tables 7 through 10 report the plans' demographically-adjusted likelihoods of receiving the various treatment paths for each medical condition.

AMI. Table 7 summarizes differences between plans in the incidence, treatment, and cost of AMI. To control for differing demographics across plans, all figures are standardized by the age and sex distribution of the GIC pool as a whole. The second row of the table shows that indemnity sufferers cost approximately 50 percent more to treat than HMO sufferers. This is true despite the fact that HMO patients are just as likely to undergo CABGs as indemnity patients (13 percent in each plan), and are substantially more likely to receive PTCAs (20 percent compared to 13 percent). The difference stems from increased treatments after a catheterization; the share of patients receiving a catheterization is the same in the two plans. That HMO patients disproportionately receive more intense treatment is contrary both to conventional wisdom and to the treatment intensity hypothesis. 
The fact that treatment intensity is greater in the HMOs suggests that this factor does not contribute to higher costs for the indemnity plan. The fourth column of Table 6 confirms that this is the case; the absence of uniform treatment differences across plans indicates that treatment effects explain only one percent of differences in AMI costs. ${ }^{13}$

One conceivable explanation for greater treatment intensity in HMO heart attack cases is that they are more severe than those in the indemnity plan. This seems unlikely, however; approximately the same percentages of patients follow the null (or non-surgical) path in the two insurance plans. A second explanation is that HMO patients may be treated in more intensive hospitals, perhaps because they are more likely to live in urban areas or because the HMOs direct their patients to particularly high-tech institutions (Feldman and Scharfstein, 1998). To test this, we estimated all of the treatment intensity models in the paper controlling for the MSA of the patient (or alternatively the zip code) and the hospital of admission. The results, shown in Appendix Tables A through D, are very similar to those reported here. Neither patient location nor hospital of admission explains the greater treatment intensity in the HMOs. The hypothesis most consistent with the evidence is that HMOs simply provide a greater treatment intensity for AMI.

Live Birth. Table 8 examines live births. Women in the indemnity plan are significantly more likely to receive a caesarian section than their counterparts in HMOs, even controlling for differences in age. The figures indicate that the age-adjusted

\footnotetext{
${ }^{13}$ It may seem puzzling that Table 7 shows more intense treatment of AMI in the HMOs, while the fraction of the difference in AMI costs due to treatments in Table 6 is positive. This arises because of variation in treatment rates within demographic groups. The treatment shares in Table 7 are adjusted for demographic differences between the individual insurance plans' pools and the total GIC pool, while those in Table 6 are
} 
caesarian section rate is one-third higher in the indemnity plan than in the HMOs. This higher caesarian section rate contributes to higher indemnity plan costs. Differences in caesarian rates explain one-ninth of cost differences between plans (Table 6). This evidence favors the treatment intensity hypothesis. Live birth is the only condition we study where indemnity patients clearly receive more intense treatment than HMO patients. Whether this results from plan actions or differential selection on the part of high-risk women is unclear.

Cancer. Table 9 shows details on the treatment of cancer in the two plans. For breast, cervical, and prostate cancer, there are no significant differences in the treatment paths between indemnity and HMO patients. In each case, a preponderance of people receive surgery alone, with the next largest share receiving surgery combined with radioactive oncology or chemotherapy. HMO patients suffering from colon cancer are more likely to receive the most intense treatment, but the share of cost differences resulting from differences in treatment intensity is small. As Table 6 shows, differences in treatment intensity account for a small fraction of differences in per capita costs (except in the case of cervical cancer, where the cost difference itself is extremely small). These results again contradict the treatment intensity hypothesis.

We also examined the likelihoods of several more minor treatments for cancer. In general, indemnity patients appear more likely to have physician visits for patient management; in addition, colon cancer patients are more likely to undergo diagnostic radiology in the indemnity plan. However, the vast majority of patients in both plans

adjusted for demographic differences between the sufferers of a given condition in the various plans. In 
receive these treatments. Because of the potentially informal nature of patient management, which could be as simple as a conversation with a primary care physician, reporting on this 'treatment' may be inconsistent across the two plans. On the other hand, these results could indicate a higher quality of 'customer care' in the indemnity plan, which may explain the anecdotal belief that indemnity plans provide better care than do HMOs.

Diabetes. Since diabetics do not naturally group into a small number of treatment paths, we do not track the incidence of specific procedures in their medical histories. As a result, we cannot present any results relating to treatment intensity for diabetes.

Summary. To summarize the treatment differences, we form a weighted average of treatment shares in the different plans, where the weights are the reimbursement of the different treatment options. For example, a comparison of treatments for condition $j$ in the HMOs and indemnity plan, using the indemnity plan's reimbursements as weights, takes the following form:

$$
\frac{\sum_{k=1}^{K_{j}} \overline{t_{j k}^{H}} \cdot \overline{r_{j k}^{I}}}{\sum_{k=1}^{K_{j}} \overline{t_{j k}^{I}} \cdot \overline{r_{j k}^{I}}}
$$

Table 6, only the adjustments for incidence mix are made at the level of the insurance plans' total pools. 
where an upper bar signifies an average of treatment rates or costs for sufferers of condition $j$ in the specified plan. Table 11 shows the results. ${ }^{14}$ The first column uses indemnity plan reimbursements as the weights; the second column uses HMO reimbursements. Whichever plan is used as the norm, the results are similar. Most of the values are less than 1 , implying that the indemnity plan is less intense than the HMOs, although the results are generally not statistically significantly different from 1 . The only statistically significant value (at the 10 percent level) is for colon cancer standardized to HMO costs, where the HMOs actually deliver more intense treatment.

A summary of treatment effects is shown in Table 6 . Driven largely by our finding of significantly more caesarian sections as a fraction of births in the indemnity plan, we calculate that treatment differences explain five percent of per case cost differences. Excluding cervical cancer, where the overall difference in treatment costs between plans is very small, the share would be cut to three percent. Treatment intensity explains a modest share of the cost differences we observe between plans.

\section{Price Effects}

We attribute differences in reimbursement dollars per sufferer that persist after controlling for demographics and treatments to differences in prices. There are two potential problems with this assumption. First, we cannot disentangle true price differences from the effects of within-demographic-group selection. For example, if indemnity patients with one of these conditions are more severely ill than HMO patients

\footnotetext{
${ }^{14}$ Confidence intervals for the ratios are calculated using a bootstrap method. We randomly assign patients to the indemnity plan or HMOs, then create a distribution of simulated treatment ratios with which to measure the likelihood that the actual ratios differ from 1.
} 
with that condition, they may use more services and thus cost more, even with prices being the same. ${ }^{15}$ This situation introduces a bias toward overstating the importance of price differences if indemnity patients are more severely ill. However, the modest differences in treatment intensity suggest that this may not be the case. Second, we do not adjust for quality of care differences across plans. A true price index would take this into account (Cutler, McClellan, and Newhouse, 2000). On the basis of our findings concerning treatment intensity, however, we suspect this is not a significant issue.

$A M I$. In the CABG, PTCA, and null paths, indemnity patients suffering from heart attacks incurred significantly more reimbursement dollars than HMO patients following the same treatment paths. To aggregate these findings, we compute a weighted average of reimbursement, using the treatment rates in the indemnity plan and HMOs combined as weights. As Table 7 shows, reimbursement per patient in the indemnity plan averages $\$ 29,488$, compared to $\$ 19,821$ for HMO patients. These differences are large; 37 percent of the differences in costs across plans for AMI are accounted for by differences in prices (Table 6). This provides strong evidence that price differentials are important.

Live Birth. Average reimbursement for the nine months preceding and week following a birth do not differ significantly between the indemnity plan and the HMOs (Table 8). However, there is a large and statistically significant difference in

\footnotetext{
${ }^{15}$ Since we only have records of principal diagnoses, it is difficult to detect the relative severity of each condition across patients.
} 
reimbursement between plans for births involving a caesarian section - a live birth in the indemnity plan generates an average of $\$ 14,937$ in payments per episode, versus only $\$ 10,072$ in the HMOs. Since this difference emerges between groups receiving the same distribution of treatments, it supports the price hypothesis. Again, close to 40 percent of total cost differences between the indemnity plan and HMOs are accounted for by differing prices.

Cancer. Average payments generated by cancer patients in the indemnity plan are significantly higher than in the HMOs for all four cancers, with (or without) adjustment for treatment differences (Table 9). For example, breast cancer patients in the indemnity plan average $\$ 27,002$ in payments over each six-month episode, while sufferers in the HMOs average only $\$ 10,878$. Payment differences are statistically significant in about half of the specific condition-treatment cells; in one quarter of the cells, small sample sizes limit the statistical significance achievable by our estimation techniques. The remaining quarter of the cells show no significant differences in payments. As Table 6 demonstrates, price differences account for approximately half of the cost differences across plans for cancers, strongly supporting the price hypothesis.

Diabetes. Total payments generated by both types of diabetics in the indemnity plan statistically significantly exceed those of their HMO-based counterparts (Table 10). Over two years, type I diabetics in the indemnity plan require $\$ 11,023$ in reimbursement while those in the HMOs require only $\$ 7,748$. For type II diabetics, this disparity is 
$\$ 6,898$ versus $\$ 4,479$. As Table 6 shows, price differences account for about one-third of total costs differences in treating diabetics.

Summary: To estimate the overall contribution of price differentials to cost differences across plans, the last column of Table 11 shows the ratio of reimbursement in the indemnity plan to reimbursement in the HMOs for each condition, adjusting for differing treatment shares in the two types of plans. The ratios are usually substantially above 1, ranging from 23 percent to 355 percent higher in the indemnity plan compared to the HMOs. The spending ratios' are statistically significantly different from 1 for five of the six conditions.

The magnitude of the difference is highlighted in the last column of Table 6. For the eight conditions for which decompositions are available, we estimate that price differences account for 45 percent of differences in plan costs.

\section{Covariance Terms}

In our decomposition of cost differences, we did not discuss covariance terms. These terms represent the shares of cost differences arising from interactions between incidence, within-condition mix, treatment, and price effects. Appendix Table F summarizes the higher-order terms from our decomposition of cost differences for AMI. For that condition, most effects are small; the same is true for most other conditions. We 
do not attach any special interpretation to these results, which are presented for completeness. ${ }^{16}$

\section{Conclusions and Implications}

We analyzed three sources of significant cost differences between the indemnity plan and the HMOs in the GIC: mix (either from demographic differences among sufferers or different incidence rates within demographic groups), treatment intensity, and prices for treatments. Table 6 summarizes our results. Incidence rates are important. Indeed, for six of the eight conditions we study, the incidence was twice as high in the indemnity plan as in the HMOs. Across the conditions, 47 percent of differences in plan costs are attributable to differences in the likelihood of patients in the two types of plans suffering from these conditions. On average, approximately three percent of the difference between plans in total costs for all conditions result from differing incidence rates for these select conditions. Conditional on having a condition, mix effects are much less important; the demographics among the suffering population are relatively similar across plans.

Price differences are the other major component, explaining 45 percent of cost differences in total. This provides strong evidence that price differentials are a key source

\footnotetext{
${ }^{16}$ In general, the interaction terms are predominantly negative. The most significant interaction is between incidence and price- plans with more people suffering a disease spend less on that disease, on average. This implies that the groups where incidence is higher in the HMOs are those for whom more expensive treatments are more common in the indemnity plan (or vice-versa). For example, incidence rates of acute myocardial infarction are much more similar across age groups in the HMOs than in the indemnity plan, but younger patients are much more likely to receive the most expensive procedures (bypass surgeries) in the indemnity plan than in the HMOs.
} 
of cost differences, although our results must be qualified by our inability to separate pure price effects from the effects of unobserved within-group selection. Finally, treatment intensity differences explain only a small part of cost differences. The indemnity plan offers more intense treatment only for births. The HMOs, in contrast, offer more intensive treatment for AMI and colon cancer.

How is it possible that HMOs have the same or higher treatment intensity, given the usual assumption that HMOs curb incentives for expenditure? It does not seem plausible that HMO patients generally have more severe cases, since both the unadjusted and age- and sex-adjusted incidences of these diseases are greater in the indemnity plan. Moreover, an alleged advantage of HMOs is that they are more vigorous in screening for diseases, which would suggest they detect less advanced cases that are presumably cheaper to treat.

We advance three possible explanations that merit investigation: (1) HMOs' genuine concern about their patients and their individual management of cases more than outweigh any adverse effects of cost-saving considerations. (2) HMOs, which tend to compete vigorously with one another, have a deep concern for their reputations; they assume that information about offering intense treatment where appropriate spreads in the marketplace. (3) Preventive care—a supposed specialty of HMOs—works, but selectively. In particular, it differentially eliminates the more mild cases of a disease. Hence treatment intensity for the remaining cases is greater than in the indemnity plan. Whatever the explanation for the surprisingly small contribution of treatment intensity to cost differences, our overall results represent good news for those policy- 
makers who contemplate saving money through managed care. It costs substantially less, without reducing the use of expensive treatments.

Our results should be complemented, of course, with studies of a broad range of medical conditions and other settings. But assuming no unpleasant surprises, we have the positive finding that cost savings by HMOs are not achieved through curtailing essential medical treatments. ${ }^{17}$ Treatment intensity, as measured by the cost of the treatments provided, is but one factor that helps to determine medical outcomes. For example, physician skill levels or patient compliance rates could differ between the two types of plans. Outcome differences between plans should also be examined. Past evidence, however, does not suggest clear conclusions about outcome differences between patients in HMOs and patients in indemnity plans (Miller and Luft, 1997).

If treatments do not differ on average between the two types of plans- or if indeed the HMOs offer more intense treatment for the money—why do older and sicker individuals differentially choose to stay in the indemnity plan? Our strong suspicion is that, not unlike many health policy analysts and economists, the employees enrolled in the GIC's health plans simply have the wrong view about which mode delivers the more intensive care. It may also be the case, though, that unmeasured aspects of the treatment environment differ and favor the indemnity plan. For example, customer satisfaction and relationships with providers may receive greater emphasis in the indemnity plan. A strong relationship with caregivers could be as important an input for patient satisfaction as the treatment itself. Alternatively, factors such as unlimited choice of physicians and

\footnotetext{
${ }^{17}$ In addition, out-of-pocket expenses are lower for high-cost patients in the HMOs; it certainly appears that HMO patients get more bang—or at least more treatment—for their medical care buck.
} 
the absence of 'gatekeeper' primary care providers may explain why high-risk patients prefer the indemnity plan.

The GIC has taken action to cut the higher costs incurred by patients in the indemnity plan. In FY1999, the GIC implemented a Market Based Reimbursement (MBRS), where its payments to hospitals and providers under the indemnity plan were more determined by a formula based on payments made by HMOs and Medicare for each DRG. The GIC estimates it has realized significant savings from this - about \$26 million in FY1999, or 10.9 percent of total plan medical claims. For FY00, savings are anticipated to be an additional 3 to 4 percent of indemnity claims. ${ }^{18}$ The cost savings created by MBRS suggest either that our price hypothesis explains a major portion of past differences in costs, or that treatment intensity is falling in the indemnity plan. We prefer the former explanation, since it is unlikely that treatments would become less intense in the indemnity plan than in the HMOs when all plans effectively face the HMOs' payment rates.

Understanding the source of cost differentials between HMO and indemnity plans should help employers decide whether and how to implement risk-adjustment in their efforts to efficiently subsidize employee health plans. Efficiency requires that prices to consumers reflect "true" differences in costs between plans. Our results for the GIC show that mix effects- which do not reflect true differences in costs—account for half of the excess cost of the indemnity plan. However price effects, which are a true cost difference, account for most of the rest.

\footnotetext{
${ }^{18}$ We are grateful to Helena Rubinstein, Director of the Policy Analysis \& Program Development at the GIC for discussing this with us and providing the financial information.
} 


\section{References}

Altman, Daniel, David M. Cutler and Richard J. Zeckhauser, "Adverse Selection and Adverse Retention," American Economic Review, Vol. 88, No. 2 (May 1998), pp. 122-126.

Cutler, David M., Mark McClellan and Joseph P. Newhouse, "What Has Increased Medical-Care Spending Bought?” American Economic Review, Vol. 88, No. 2 (May 1998), pp.132-136.

Cutler, David M., Mark McClellan and Joseph P. Newhouse, "How Does Managed Care Do It?” RAND Journal of Economics, forthcoming (2000).

Cutler, David M. and Richard J. Zeckhauser, “Adverse Selection in Health Insurance," in Alan M. Garber, ed., Frontiers in Health Policy Research, Vol. 1 (Cambridge, MA: MIT Press, 1998).

Eichner, Matthew, Mark McClellan, and David A. Wise, "The Sources of Cost Difference in Health Insurance Plans: A Decomposition Analysis," National Bureau of Economic Research Working Paper Series, No. 7443 (December, 1999).

Feldman, Sarah and David Scharfstein, "Managed Care Provider Volume," National Bureau of Economic Research Working Paper Series, No. 6523 (April, 1998).

Ellis, Randall P., "Employee Choice of Health Insurance," Review of Economics and Statistics, Vol. 71, No. 2 (May 1989), pp. 215-223.

Jackson-Beeck, Marilyn and John H. Kleinman, "Evidence for self-selection among health maintenance organization enrollees," Journal of the American Medical Association, Vol. 250, No. 20 (November 25, 1983), pp. 2826-29.

Langwell, Katherine M. and James P. Hadley, "Evaluation of the Medicare competition demonstrations," Health Care Financing Review, Vol. 11, No. 2 (Winter 1989), pp. $65-80$.

Miller, Robert H. and Harold S. Luft, "Managed care plan performance since 1980," Journal of the American Medical Association, Vol. 271, No. 19 (May 18, 1994), p. 1512.

Miller, Robert H. and Harold S. Luft, "Does managed care lead to better or worse quality of care?” Health Affairs, Vol. 16, No. 5 (September/October 1997), pp. 7-25. 
Scitovsky, Anne A., Nelda McCall and Lee Benham, "Factors affecting the choice between two prepaid plans," Medical Care, Vol. 16, No. 8 (August 1978), pp. 660-675. 
TABLE 1 - GIC Plan PREMIUMS, ENROLLMENT, AND BENEFIT COSTS FOR FisCAL YeAR 1995

\begin{tabular}{lccc}
\hline Plan Group & Premium (\$) & Enrollment & Benefit Cost (\$) \\
\hline Indemnity & 2,670 & 67,789 & 2,638 \\
PPO & 1,631 & 25,077 & 1,340 \\
HMOs & 1,686 & 122,421 & 1,226 \\
\hline
\end{tabular}

Note: Enrollment and benefit costs include only individuals under age 65. Premiums and benefit costs represent means over entire plan groups. 
TABLE 2 - SUMMARY OF MEDICAL CONDITIONS EXAMINED

\begin{tabular}{|c|c|c|c|c|}
\hline \multicolumn{2}{|l|}{ Condition } & Demographic Universe & Major Treatments & Claim Identification \\
\hline \multicolumn{2}{|c|}{$\begin{array}{l}\text { Acute myocardial } \\
\text { infarction (AMI) }\end{array}$} & men and women, 30-64 & $\begin{array}{l}\text { cardiac catheterization, } \\
\text { alone or accompanied by } \\
\text { either percutaneous } \\
\text { transluminal coronary } \\
\text { angioplasty (PTCA) or } \\
\text { coronary artery bypass } \\
\text { graft (CABG); patients } \\
\text { could receive none of } \\
\text { the above }\end{array}$ & $\begin{array}{l}\text { all claims within } 90 \text { days } \\
\text { of diagnosis of an AMI }\end{array}$ \\
\hline \multicolumn{2}{|l|}{ Live birth } & eligible mothers, $15-44$ & $\begin{array}{l}\text { normal delivery or } \\
\text { caesarian section }\end{array}$ & $\begin{array}{l}\text { births identified as new } \\
\text { enrollees with birthdate } \\
\text { within fiscal year; } \\
\text { eligible mothers are } \\
\text { female heads-of- } \\
\text { household or spouses } \\
\text { ages } 15-44 \text {; all claims } \\
\text { from nine months before } \\
\text { the birth through seven } \\
\text { days after the birth }\end{array}$ \\
\hline Cancers: & $\begin{array}{l}\text { breast } \\
\text { colon } \\
\text { cervix } \\
\text { prostate }\end{array}$ & $\begin{array}{l}\text { women, 30-64 } \\
\text { men and women, 30-64 } \\
\text { women, 30-64 } \\
\text { men, 30-64 }\end{array}$ & $\begin{array}{l}\text { surgery and/or } \\
\text { radioactive oncology } \\
\text { and chemotherapy, or } \\
\text { none of the above }\end{array}$ & $\begin{array}{l}\text { all claims within six } \\
\text { months of first cancer } \\
\text { diagnosis for patients } \\
\text { with at least two } \\
\text { diagnoses for the same } \\
\text { type of cancer }\end{array}$ \\
\hline \multicolumn{2}{|c|}{$\begin{array}{l}\text { Diabetes } \\
\text { (type I (juvenile) and } \\
\text { type II (adult-onset)) }\end{array}$} & men and women, 0-64 & - & $\begin{array}{l}\text { all claims over two fiscal } \\
\text { years for individuals } \\
\text { with at least two } \\
\text { diabetes-related } \\
\text { diagnoses }\end{array}$ \\
\hline
\end{tabular}

Note: Diagnoses are identified using codes from the International Classification of Diseases, $9^{\text {th }}$ Edition, Clinical Modification (ICD9-CM). Procedures are identified using codes from the Physician's Current Procedural Terminology and the ICD9-CM. 
TABLE 3 - DEMOGRAPHIC Distributions OF GIC ENROLLEES BY INSURANCE PlAN GROUP, FY95

\begin{tabular}{|c|c|c|c|c|}
\hline \multirow[b]{2}{*}{ Age Group } & \multicolumn{2}{|c|}{ Indemnity Plan } & \multicolumn{2}{|c|}{ HMOs } \\
\hline & Males & Females & Males & Females \\
\hline $0-19$ & $9.00 \%$ & $8.65 \%$ & $12.68 \%$ & $16.28 \%$ \\
\hline $20-34$ & 6.26 & 7.15 & 9.76 & 12.03 \\
\hline $35-49$ & 12.51 & 16.13 & 14.59 & 16.43 \\
\hline $50-64$ & 15.47 & 19.80 & 6.77 & 7.28 \\
\hline All ages & $45.78 \%$ & $54.22 \%$ & $47.99 \%$ & $52.01 \%$ \\
\hline Enrollees & \multicolumn{2}{|c|}{67,789} & \multicolumn{2}{|c|}{122,421} \\
\hline
\end{tabular}

Note: Each entry is the share of that plan's enrollees in that age and sex group.

TABle 4 - Summary of InCidenCe Rates of Major Conditions by Plan, FY94-95

\begin{tabular}{|c|c|c|c|c|c|c|}
\hline \multirow[b]{2}{*}{ Condition } & \multicolumn{3}{|c|}{ Overall Incidence } & \multicolumn{3}{|c|}{$\begin{array}{l}\text { Incidence Adjusted for } \\
\text { Demographics }\end{array}$} \\
\hline & Indem. & HMOs & Ratio & Indem. & HMOs & Ratio \\
\hline Acute myocardial infarction & $0.67 \%$ & $0.30 \%$ & $2.23 *$ & $0.54 \%$ & $0.40 \%$ & $1.35^{*}$ \\
\hline Live birth & 6.09 & 5.05 & $1.21 *$ & 6.80 & 4.82 & $1.41 *$ \\
\hline Breast cancer & 1.33 & 0.59 & $2.25^{*}$ & 1.12 & 0.72 & $1.56^{*}$ \\
\hline Cervical cancer & 0.13 & 0.13 & 0.93 & 0.14 & 0.13 & 1.08 \\
\hline Colon cancer & 0.21 & 0.08 & $2.62 *$ & 0.16 & 0.10 & $1.60^{*}$ \\
\hline Prostate cancer & 0.75 & 0.26 & $2.88^{*}$ & 0.52 & 0.38 & $1.37^{*}$ \\
\hline Type I diabetes & 1.39 & 0.55 & $2.53 *$ & 1.18 & 0.65 & $1.82 *$ \\
\hline Type II diabetes & 2.33 & 1.07 & $2.18^{*}$ & 1.76 & 1.36 & $1.29 *$ \\
\hline
\end{tabular}

* Denotes that the ratio of the indemnity plan rate to HMOs' rate is significantly different from one at the five percent level.

Note: Demographic adjustments follow the formula described in section III.A (Mix Effects: Incidence). The universes of enrollees for each condition are described in Table 2. 
TABle 5 - COMPARISONS OF CONDITION-SPECIFIC COSTS AND TOTAL COSTS From All DiseASES WITH THE EFFECT OF INCIDENCE RATES, FY94-95

\begin{tabular}{|c|c|c|c|c|}
\hline $\begin{array}{l}\text { Costs Per Capita, Sum of FY94 } \\
\text { and FY95, by Universe of } \\
\text { Enrollees and Condition(s) }\end{array}$ & $\begin{array}{c}\text { Indemnity } \\
\text { Plan }\end{array}$ & HMOs & $\begin{array}{c}\text { Indemnity Plan } \\
\text { With HMO } \\
\text { Incidence } \\
\text { Rates } \\
\end{array}$ & $\begin{array}{c}\text { Percent of } \\
\text { Difference in } \\
\text { Total Costs } \\
\text { from Incidence }\end{array}$ \\
\hline \multicolumn{5}{|l|}{ Men and women aged 0-64: } \\
\hline Total costs & $\$ 5,232$ & $\$ 2,277$ & $\$-$ & $\$-$ \\
\hline Costs from Type I diabetes & 158 & 105 & 62 & 3.2 \\
\hline Costs from Type II diabetes & 167 & 97 & 77 & 3.0 \\
\hline \multicolumn{5}{|l|}{ Men and women aged 30-64: } \\
\hline Total costs & 6,449 & 2,861 & - & - \\
\hline Costs from AMI & 200 & 57 & 90 & 3.1 \\
\hline Costs from colon cancer & 65 & 9 & 24 & 1.1 \\
\hline \multicolumn{5}{|l|}{ Men aged 30-64: } \\
\hline Total costs & 6,011 & 2,451 & - & - \\
\hline Costs from prostate cancer & 128 & 28 & 44 & 2.4 \\
\hline \multicolumn{5}{|l|}{ Women aged 30-64: } \\
\hline Total costs & 6,793 & 3,223 & - & - \\
\hline Costs from breast cancer & 342 & 69 & 151 & 5.3 \\
\hline Costs from cervical cancer & 20 & 11 & 22 & -0.1 \\
\hline \multicolumn{5}{|l|}{ Eligible mothers aged $15-44:$} \\
\hline Total costs & 6,007 & 2,956 & - & - \\
\hline Costs from live births & 582 & 430 & 482 & 3.3 \\
\hline
\end{tabular}

Note: Total costs are sums of FY94 and FY95 per capita costs within the noted universes of patients. The last column shows what percentage of total costs (for all conditions) is accounted for by incidence rates of the condition in question. These figures are not adjusted for specific demographic characteristics. 
TABle 6 - Summary of Decompositions of Cost Differences Between Plans Among Sufferers, FY94-95

\begin{tabular}{|c|c|c|c|c|c|}
\hline \multirow[b]{2}{*}{ Condition } & \multirow[b]{2}{*}{$\begin{array}{c}\text { Difference in } \\
\text { Per Capita } \\
\text { Plan Costs, } \\
\text { Indemnity - } \\
\text { HMO* }\end{array}$} & \multicolumn{2}{|c|}{ Mix Effect } & \multirow[b]{2}{*}{$\begin{array}{l}\text { Percent of } \\
\text { Difference } \\
\text { from } \\
\text { Treatment } \\
\text { Intensity }\end{array}$} & \multirow[b]{2}{*}{$\begin{array}{l}\text { Percent of } \\
\text { Difference } \\
\text { from Price or } \\
\text { Unobserved } \\
\text { Selection }\end{array}$} \\
\hline & & $\begin{array}{c}\text { Percent of } \\
\text { Difference } \\
\text { from } \\
\text { Incidence Mix }\end{array}$ & $\begin{array}{c}\text { Percent of } \\
\text { Difference } \\
\text { from Within- } \\
\text { Condition Mix }\end{array}$ & & \\
\hline Average & $\$ 107$ & $46.8 \%$ & $4.2 \%$ & $5.1 \%$ & $45.1 \%$ \\
\hline $\begin{array}{l}\text { Acute } \\
\text { myocardial } \\
\text { infaction }\end{array}$ & 143 & 57.6 & 4.5 & 1.0 & 36.9 \\
\hline Live birth & 152 & 51.4 & 0.4 & 11.3 & 36.9 \\
\hline Breast cancer & 273 & 51.9 & -6.7 & 1.2 & 53.6 \\
\hline Cervical cancer & 9 & -10.6 & 24.4 & 14.4 & 71.8 \\
\hline Colon cancer & 56 & 46.1 & -5.0 & 5.3 & 53.6 \\
\hline Prostate cancer & 100 & 58.2 & 6.3 & -2.5 & 38.0 \\
\hline Type I diabetes & 53 & 64.3 & 4.1 & - & 31.5 \\
\hline Type II diabetes & 70 & 55.8 & 5.6 & - & 38.6 \\
\hline
\end{tabular}

Note: The percentages in the last four columns refer only to relative importances of the first-order effects from the decompositions. Appendix Table E lists the actual first-order effects. "Per capita" refers only to the universe of enrollees in which the condition is examined; see Table 2 for details. Costs are totals for FY94 and FY95. 
TABLE 7 - FREQUENCY OF TREATMENTS AND PAYMENTS FOR ACUTE MYOCARDIAL INFARCTION (AMI) BY PLAN, FY94-95

\begin{tabular}{lcr}
\hline Plan & Indemnity & HMOs \\
$\begin{array}{l}\text { Two-year incidence of AMI* } \\
\text { Average cost per episode* }\end{array}$ & & $0.40 \%$ \\
Share by treatment path & $0.54 \%$ & $\$ 19,821$ \\
$\quad$ null & $\$ 29,488$ & \\
$\quad$ catheterization* & & $53.4 \%$ \\
PTCA* & $52.0 \%$ & 13.2 \\
$\quad$ CABG & 22.3 & 20.0 \\
& 13.1 & 13.4 \\
Payments, AMI episodes & 12.6 & \\
By path: & & $\$ 10,573$ \\
$\quad$ catheterization & & 21,939 \\
$\quad$ PTCA* & $\$ 17,882$ & 21,302 \\
CABG* & 25,151 & 51,885 \\
weighted by treatment path* & 40,662 & 19,282 \\
& 72,693 & \\
\hline
\end{tabular}

* Denotes that means are significantly different at the five percent level.

Note: All figures are demographically adjusted for the age and sex composition of the total insurance pool. This analysis includes only individuals between the ages of 30 and 64. Payments refer to all services and prescription drugs within 90 days from the date of diagnosis of the AMI. CABG is coronary artery bypass graft surgery. PTCA is percutaneous transluminal coronary angioplasty. Catheterization refers to instances in which the patient underwent a cardiac catheterization but not CABG or PTCA. The null path indicates none of the three major surgical treatments were undertaken. Nine cases in which patients underwent both PTCA and CABG were classified as CABG.

TABLE 8 - FREQUENCY OF TREATMENTS AND PAYMENTS FOR LIVE BIRTHS BY PLAN, FY94-95

\begin{tabular}{lrr}
\hline Plan & Indemnity & HMOs \\
\hline Incidence of live birth* & & \\
Average cost per birth & $6.80 \%$ & $4.82 \%$ \\
& $\$ 9,624$ & $\$ 8,446$ \\
Caesarian section share* & $22.9 \%$ & $17.0 \%$ \\
& & \\
Payments, pregnancy episodes & & $\$ 10,072$ \\
$\quad$ with caesarian* & $\$ 14,937$ & 8,054 \\
no caesarian & 7,810 & 8,438 \\
weighted by treatment path & 9,376 & \\
\end{tabular}

* Denotes that means are significantly different at the five percent level.

Note: All figures are demographically adjusted for the age composition of the total insurance pool. This analysis includes only women between the ages of 15 and 44 classified as heads-of-household or heads' spouses. Payments refer to all services and prescription drugs from nine months before a normal birth through seven days after the birth. All pregnancies resulting in births between 4/1/94 and 6/31/95 are included. 
TABLE 9 - FREQUENCY OF TREATMENTS AND PAYMENTS FOR FOUR CANCERS BY PLAN, FY94-95

\begin{tabular}{|c|c|c|c|c|c|c|c|c|}
\hline \multirow{2}{*}{$\begin{array}{l}\text { Cancer } \\
\text { Plan }\end{array}$} & \multicolumn{2}{|c|}{ Breast } & \multicolumn{2}{|c|}{ Cervix } & \multicolumn{2}{|c|}{ Colon } & \multicolumn{2}{|c|}{ Prostate } \\
\hline & Indemnity & HMOs & Indemnity & HMOs & Indemnity & HMOs & Indemnity & HMOs \\
\hline Incidence & $1.12 \%$ & $0.72 \% *$ & $0.14 \%$ & $0.13 \%$ & $0.16 \%$ & $0.10 \% *$ & $0.52 \%$ & $0.38 \% *$ \\
\hline Average cost per episode & $\$ 26,562$ & $\$ 10,935^{*}$ & $\$ 13,925$ & $\$ 7,308^{*}$ & $\$ 33,510$ & $\$ 8,816^{*}$ & $\$ 17,504$ & $\$ 11,023^{*}$ \\
\hline \multicolumn{9}{|l|}{ Share by treatment path } \\
\hline $\mathrm{RO} / \mathrm{C}$ & $3.8 \%$ & $3.0 \%$ & $1.3 \%$ & $1.2 \%$ & $5.0 \%$ & $1.4 \%$ & $7.5 \%$ & $7.4 \%$ \\
\hline surgery & 64.1 & 62.2 & 96.7 & 95.6 & 76.1 & 65.2 & 83.2 & 80.2 \\
\hline surgery-RO/C & 32.1 & 34.8 & 3.2 & 3.2 & 18.9 & $33.4^{*}$ & 9.3 & 12.4 \\
\hline \multicolumn{9}{|l|}{ Share with treatment } \\
\hline patient management & 99.2 & $97.0^{*}$ & 98.9 & $90.3^{\#}$ & 96.4 & $79.9 *$ & 98.5 & 95.8 \\
\hline diagnostic radiology & 95.1 & 92.7 & 64.4 & 64.7 & 84.2 & $70.0^{*}$ & 82.1 & 74.8 \\
\hline \multicolumn{9}{|l|}{ Payments by episode } \\
\hline by path: $\quad \mathrm{RO} / \mathrm{C}$ & $\$ 17,331$ & $\$ 8,866$ & $\underline{-}^{+}$ & $\underline{-}^{+}$ & $\$ 25,953$ & $-^{+}$ & $\$ 15,123$ & $\$ 27,593$ \\
\hline surgery & 19,473 & $5,830 *$ & 12,577 & $5,968^{*}$ & 28,129 & $2,010^{*}$ & 15,320 & $8,137^{*}$ \\
\hline surgery-RO/C & 41,728 & $20,714^{*}$ & 47,851 & $-^{+}$ & 54,936 & $25,546^{*}$ & 36,114 & 23,796 \\
\hline weighted by treatment path & 27,002 & $10,878^{*}$ & 13,890 & $7,182 *$ & 33,884 & $6,140^{*}$ & 17,871 & $10,854^{*}$ \\
\hline
\end{tabular}

\# Denotes that means are significantly different at the 10 percent level.

* Denotes that means are significantly different at the five percent level.

${ }^{+}$Denotes that the figures in this line are computed using insufficient observations to test confidence.

Note: All figures are demographically adjusted for the age and sex composition of the total insurance pool. This analysis includes only individuals between the ages of 30 and 64-women only for breast and cervical cancer, men only for prostate cancer, and both men and women for colon cancer. Payments include all services and prescription drugs within six-months from the first date of a service with a relevant cancer diagnosis and a surgery, radioactive oncology, or chemotherapy treatment. $\mathrm{RO} / \mathrm{C}$ is radioactive oncology or chemotherapy. The treatment paths are mutually exclusive. 


\begin{tabular}{llcr}
\hline Plan & & Indemnity & HMOs \\
\hline \multirow{2}{*}{ Incidence: } & type I* & $1.16 \%$ & $0.66 \%$ \\
& type II* & 1.71 & 1.36 \\
& & & $\$ 7,748$ \\
Payments: & type I* & $\$ 11,023$ & 4,479 \\
& type II* & 6,898 & \\
& & & \\
\end{tabular}

* Denotes that means are significantly different at the five percent level.

Note: All figures are demographically adjusted for the age and sex composition of the total insurance pool. This analysis includes individuals between the ages of 0 and 64. Payments include all services and prescription drugs within the two fiscal years of data. Patients were identified as diabetics if they had two services with diabetes-related diagnoses within the two-year period. Type I diabetes is juvenile, insulindependent diabetes; type II is adult-onset, non-insulin-dependent diabetes.

TABLE 11 - ALTERNATE COMPARISONS OF TREATMENT INTENSITY AND COSTS FOR SIX CONDITIONS

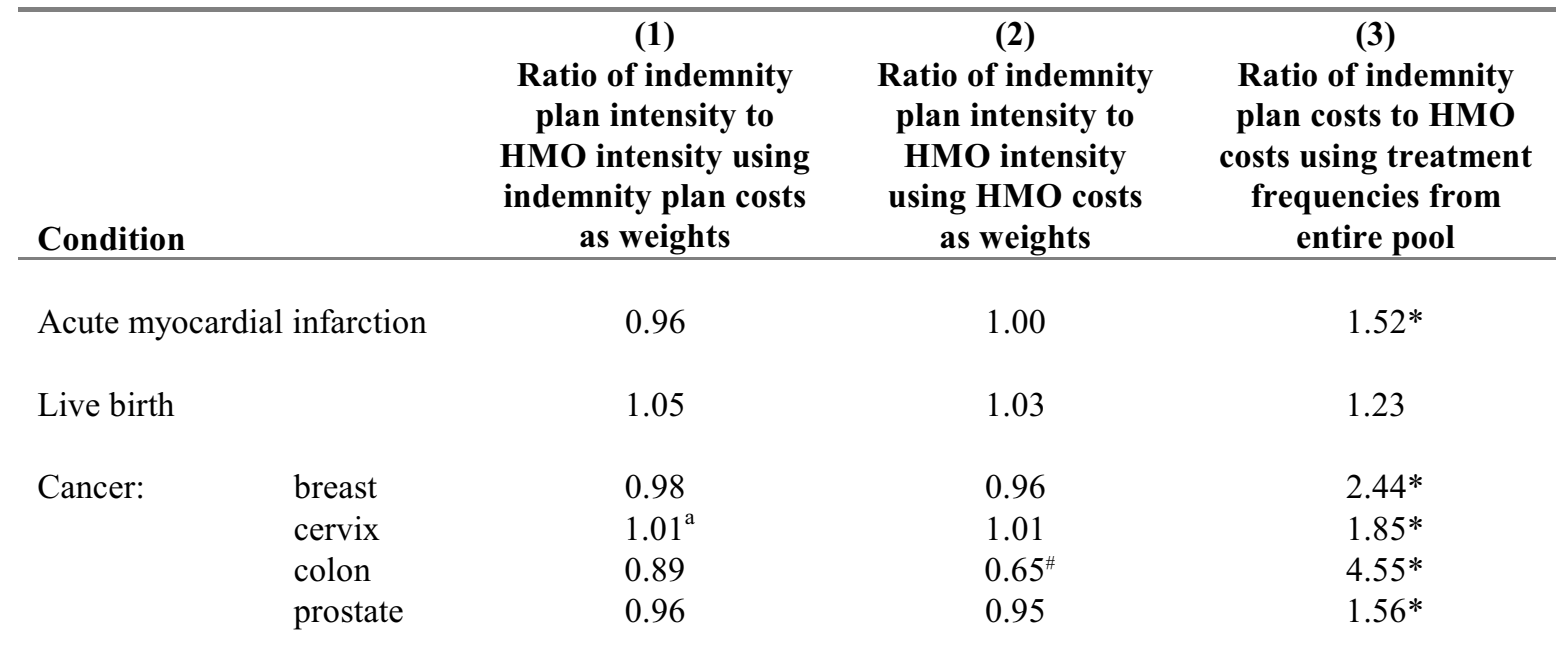

\footnotetext{
\# Denotes that ratio is significantly different from 1 at the ten percent level.

* Denotes that ratio is significantly different from 1 at the five percent level.

${ }^{a}$ Denotes that this figure is approximate because no patients in the indemnity plan followed the RO/C path. Costs for $\mathrm{RO} / \mathrm{C}$ were approximated by multiplying the average costs for surgery by the ratio in the HMOs of $\mathrm{RO} / \mathrm{C}$ costs to surgery costs.

Note: The method for computing the indices is described in section IV. The index numbers for cancers of the cervix and colon should be viewed as approximate, since the underlying figures were computed from too few observations to test confidence of differences across plans.
} 
APPENDIX TABLE A - FREQUENCY OF TREATMENTS AND PAYMENTS FOR ACUTE MYOCARDIAL INFARCTION (AMI) BY PLAN, ADJUSTED FOR AREA OF RESIDENCE AND HOSPITAL OF TREATMENT, FY94-95

\begin{tabular}{|c|c|c|}
\hline Plan & Indemnity & HMOs \\
\hline Two-year incidence of AMI* & $0.54 \%$ & $0.40 \%$ \\
\hline Average cost per episode* & $\$ 30,060$ & $\$ 18,440$ \\
\hline \multicolumn{3}{|l|}{ Share by treatment path } \\
\hline null & $52.6 \%$ & $52.3 \%$ \\
\hline catheterization* & 21.7 & 13.9 \\
\hline PTCA* & 13.4 & 20.5 \\
\hline CABG & 12.4 & 13.3 \\
\hline \multicolumn{3}{|l|}{ Payments, AMI episodes } \\
\hline treatment path: null* & $\$ 18,315$ & $\$ 8,242$ \\
\hline catheterization & 27,044 & 18,892 \\
\hline PTCA* & 42,348 & 23,355 \\
\hline $\mathrm{CABG}^{*}$ & 75,854 & 47,273 \\
\hline weighted by treatment path* & 30,487 & 17,961 \\
\hline
\end{tabular}

* Denotes that means are significantly different at the five percent level.

Note: All figures are demographically adjusted for the age and sex composition of the total insurance pool. Additional fixed effects are included for three-digit zip code of residence, Metropolitan Statistical Area of residence, and treatment at any of 10 major Massachusetts hospitals. This analysis includes only individuals between the ages of 30 and 64. Payments refer to all services and prescription drugs within 90 days from the date of diagnosis of the AMI. CABG is coronary artery bypass graft surgery. PTCA is percutaneous transluminal coronary angioplasty. Catheterization refers to instances in which the patient underwent a cardiac catheterization but not CABG or PTCA. The null path indicates none of the three major surgical treatments were undertaken. Nine cases in which patients underwent both PTCA and CABG were classified as $\mathrm{CABG}$. 
APPENDIX TABLE B - FREQUENCY OF TREATMENTS AND PAYMENTS FOR LIVE BIRTHS BY PLAN, AdJUSTED FOR AREA OF RESIDENCE AND HOSPITAL OF TREATMENT, FY94-95

\begin{tabular}{|c|c|c|}
\hline Plan & Indemnity & HMOs \\
\hline Incidence of live birth* & $6.84 \%$ & $4.77 \%$ \\
\hline Average cost per birth & $\$ 10,050$ & $\$ 9,307$ \\
\hline Caesarian sections/live births & $25.7 \%$ & $22.9 \%$ \\
\hline \multicolumn{3}{|l|}{ Payments, pregnancy episodes } \\
\hline with caesarian* & $\$ 14,879$ & $\$ 10,438$ \\
\hline no caesarian & 8,203 & 9,159 \\
\hline weighted by treatment path & 9,976 & 9,320 \\
\hline
\end{tabular}

* Denotes that means are significantly different at the five percent level.

Note: All figures are demographically adjusted for the age composition of the total insurance pool.

Additional fixed effects are included for three-digit zip code of residence, Metropolitan Statistical Area of residence, and treatment at any of 10 major Massachusetts hospitals. This analysis includes only women between the ages of 15 and 44 classified as heads-of-household or heads' spouses. Payments refer to all services and prescription drugs from nine months before a normal birth through seven days after the birth. Only pregnancies resulting in births between 4/1/94 and 6/31/95 are included. 
APPENDIX TABLE C - FREQUENCY OF TREATMENTS AND PAYMENTS FOR FOUR CANCERS BY PLAN, ADJUSTED FOR AREA OF RESIDENCE, FY94-95

\begin{tabular}{|c|c|c|c|c|c|c|c|c|}
\hline \multirow{2}{*}{$\begin{array}{l}\text { Cancer } \\
\text { Plan }\end{array}$} & \multicolumn{2}{|c|}{ Breast } & \multicolumn{2}{|c|}{ Cervix } & \multicolumn{2}{|c|}{ Colon } & \multicolumn{2}{|c|}{ Prostate } \\
\hline & Indemnity & HMOs & Indemnity & HMOs & Indemnity & HMOs & Indemnity & HMOs \\
\hline Incidence & $1.12 \%$ & $0.72 \% *$ & $0.13 \%$ & $0.13 \%$ & $0.16 \%$ & $0.10 \% *$ & $0.53 \%$ & $0.37 \% *$ \\
\hline Average cost per episode & $\$ 26,011$ & $\$ 11,410^{*}$ & $\$ 15,492$ & $\$ 8,486$ & $\$ 35,636$ & $\$ 4,932 *$ & $\$ 18,098$ & $\$ 10,109 *$ \\
\hline \multicolumn{9}{|l|}{ Share by treatment path } \\
\hline $\mathrm{RO} / \mathrm{C}$ & $3.7 \%$ & $2.9 \%$ & $0.0 \%$ & $1.8 \%$ & $5.3 \%$ & $0.6 \%{ }^{\#}$ & $8.0 \%$ & $6.7 \%$ \\
\hline surgery & 64.3 & 62.6 & 92.5 & 96.4 & 76.0 & 66.6 & 81.7 & 82.5 \\
\hline surgery-RO/C & 32.0 & 34.4 & 7.5 & 1.8 & 18.7 & 32.8 & 10.3 & 10.8 \\
\hline \multicolumn{9}{|l|}{ Share with treatment } \\
\hline patient management & 99.2 & $96.8 *$ & 96.1 & 90.8 & 96.9 & $79.1 *$ & 98.7 & 95.6 \\
\hline diagnostic radiology & 95.5 & 92.7 & 79.6 & 69.3 & 84.1 & 71.0 & 81.9 & 74.9 \\
\hline \multicolumn{9}{|l|}{ Payments by episode } \\
\hline by path: $\quad \mathrm{RO} / \mathrm{C}$ & $\$ 15,494$ & $\$ 7,906$ & - & $\underline{-}^{+}$ & $\$ 25,953$ & $ـ^{+}$ & $\$ 21,230$ & $\$ 14,354$ \\
\hline surgery & 18,803 & $6,851 *$ & 12,116 & 7,458 & 30,232 & $-2,546^{*}$ & 15,785 & $7,398 *$ \\
\hline surgery-RO/C & 38,911 & $23,205^{*}$ & 47,851 & $53,058^{*}$ & 63,083 & $15,983^{*}$ & 40,291 & 18,402 \\
\hline weighted by treatment path & 26,425 & $11,374^{*}$ & 14,165 & 8,944 & 37,157 & $2,268 *$ & 18,261 & $10,245^{*}$ \\
\hline
\end{tabular}

" Denotes that means are significantly different at the 10 percent level.

* Denotes that means are significantly different at the five percent level.

${ }^{+}$Denotes that the figures in this line are computed using insufficient observations to test confidence.

Note: All figures are demographically adjusted for the age and sex composition of the total insurance pool. Additional fixed effects are included for three-digit zip code of residence and Metropolitan Statistical Area of residence. This analysis includes only individuals between the ages of 30 and $64-$ women only for breast and cervical cancer, men only for prostate cancer, and both men and women for colon cancer. Payments include all services and prescription drugs within six-months from the first date of a service with a relevant cancer diagnosis and a surgery, radioactive oncology, or chemotherapy treatment. $\mathrm{RO} / \mathrm{C}$ is radioactive oncology or chemotherapy. Some figures are negative as a result of small sample sizes where regression estimation with so few degrees of freedom is less precise. The lack of degrees of freedom also results in some perfectly-specified regressions. 
APPENDIX TABLE D - INCIDENCE AND PAYMENTS FOR DiABETICS BY Plan, ADJUSTED FOR AREA OF RESIDENCE, FY94-95

\begin{tabular}{llcc}
\hline Plan & & Indemnity & HMOs \\
\hline \multirow{2}{*}{ Incidence: } & type I* & $1.18 \%$ & $0.65 \%$ \\
& type II* & 1.73 & 1.34 \\
& & & \\
Payments: & type I* & $\$ 10,915$ & $\$ 7,858$ \\
& type II* & 6,911 & 4,417 \\
& & &
\end{tabular}

* Denotes that means are significantly different at five percent level.

Note: All figures are demographically adjusted for the age and sex composition of the total insurance pool. Additional fixed effects are included for three-digit zip code of residence and Metropolitan Statistical Area of residence. This analysis includes only individuals between the ages of 0 and 64 . Payments include all services and prescription drugs within the two fiscal years of data. Patients were marked as diabetics if they had two services with diabetes-related diagnoses within the two-year period. Type I diabetes is juvenile, insulin-dependent diabetes; type II is adult-onset, non-insulin-dependent diabetes.

APPEndix TABle E - Decomposition of Cost DifFerences Between Plans Among SufFerers, ACTUAL FIRST-ORDER TERMS, FY94-95

\begin{tabular}{lccccc}
\hline & $\begin{array}{c}\text { Difference in } \\
\text { Per Capita } \\
\text { Plan Costs, } \\
\text { Indemnity - } \\
\text { HMO* }\end{array}$ & $\begin{array}{c}\text { Percent of } \\
\text { Difference } \\
\text { from } \\
\text { Incidence Mix }\end{array}$ & $\begin{array}{c}\text { Percent of } \\
\text { Difference } \\
\text { from Within- } \\
\text { Condition Mix }\end{array}$ & $\begin{array}{c}\text { Percent of } \\
\text { Difference } \\
\text { from } \\
\text { Treatment } \\
\text { Intensity }\end{array}$ & $\begin{array}{c}\text { Percent of } \\
\text { Difference } \\
\text { from Price or } \\
\text { Unobserved } \\
\text { Selection }\end{array}$ \\
\hline Average & $\$ 106.9$ & $83.3 \%$ & $7.1 \%$ & $7.0 \%$ & $73.2 \%$ \\
Acute & & & & & \\
myocardial & 143.4 & 77.0 & 6.0 & 1.3 & 49.4 \\
infaction & 151.7 & 65.5 & 0.5 & 14.4 & 47.1 \\
Live birth & 272.6 & 69.7 & -9.0 & 1.6 & 71.9 \\
Breast cancer & 9.8 & -14.5 & 33.3 & 19.7 & 98.0 \\
Cervical cancer & 55.7 & 73.5 & -8.0 & 8.4 & 85.5 \\
Colon cancer & 100.1 & 83.8 & 9.0 & -3.6 & 54.7 \\
Prostate cancer & & 181.3 & 11.6 & - & 88.9 \\
Type I diabetes & 52.6 & 129.8 & 13.1 & - & 89.8 \\
Type II diabetes & 69.5 & & & & \\
\hline
\end{tabular}

Note: Sum of components of differences may exceed 100 percent since second-order and third-order terms are omitted. Appendix Table F lists all terms for acute myocardial infarction. Components may be negative if adjusting for the given variable widens the gap in costs between the health plans. "Per capita" refers only to the universe of enrollees in which the condition is examined; see Table 2 for details. Costs are totals for FY94 and FY95. 
APPENDIX TABLE F — COMPLETE LIST OF TERMS FROM DECOMPOSITION OF COST DifFERENCES, ACUTE MYOCARDIAL INFARCTION, FY94-95

\begin{tabular}{|c|c|}
\hline Decomposed Term & $\begin{array}{l}\text { Percentage of Cost } \\
\text { Difference Explained }\end{array}$ \\
\hline incidence & 77.0 \\
\hline within-condition mix & 6.0 \\
\hline treatments & 1.3 \\
\hline price & 49.4 \\
\hline (incidence)*(within-condition mix) & -3.3 \\
\hline (incidence)*(treatments) & -0.7 \\
\hline (incidence)*(price) & -27.3 \\
\hline (within-condition mix)*(treatments) & 5.8 \\
\hline$(\text { within-condition mix })^{*}($ price $)$ & -1.5 \\
\hline$($ treatments $) *($ price $)$ & -2.8 \\
\hline$($ incidence $) *(\text { within-condition mix })^{*}$ (treatments) & -3.2 \\
\hline$(\text { incidence })^{*}(\text { within-condition mix })^{*}($ price $)$ & 0.8 \\
\hline$($ incidence $) *($ treatments $) *($ price $)$ & 1.6 \\
\hline$(\text { within-condition mix })^{*}($ treatments $) *($ price $)$ & -6.8 \\
\hline (incidence) $^{*}($ within-condition mix $) *($ treatments $) *($ price $)$ & 3.7 \\
\hline Total (without rounding) & 100.0 \\
\hline
\end{tabular}

Note: This analysis includes only individuals between the ages of 30 and 64. Costs refer to payments for all services and prescription drugs within 90 days from the date of diagnosis of the AMI. Components may be negative if adjusting for the given variables widens the gap in costs between the health plans. 


\section{Mathematical Appendix - Hypothetical Calculation of Sources of Cost Differences}

The formula for per capita costs for condition $j$ in plan $P$ is $x_{j}^{P}=q_{j}^{P} \cdot \sum_{i=1}^{N}\left(d_{i j}^{P} \cdot \sum_{k=1}^{K} t_{i j k}^{P} \cdot r_{i j k}^{P}\right)$.

Let $P \in\{I, H\}, N=2$, and $K=2$; we can suppress subscript $j$ for considering one hypothetical condition.

Let $q^{I}=0.2$ and $q^{H}=0.1$ be the incidence rates in the two plans.

Let the demographic distributions conditional on contracting the condition be $d^{I}=\left[\begin{array}{ll}0.4 & 0.6\end{array}\right]$ in the indemnity plan and $d^{H}=\left[\begin{array}{ll}0.3 & 0.7\end{array}\right]$ in the HMOs.

Let the distributions of treatments conditional on demographics and on contracting the condition be $t^{I}=\left[\begin{array}{ll}0.6 & 0.8 \\ 0.4 & 0.2\end{array}\right]$ in the indemnity plan and $t^{H}=\left[\begin{array}{ll}0.5 & 0.7 \\ 0.5 & 0.3\end{array}\right]$ in the HMOs.

Let mean payments conditional on treatments, demographics, and contracting the condition be $r^{I}=\left[\begin{array}{ll}2 & 6 \\ 4 & 8\end{array}\right]$ in the indemnity plan and $r^{H}=\left[\begin{array}{ll}1 & 5 \\ 3 & 7\end{array}\right]$ in the HMOs.

Then $x^{I}=0.99$ and $x^{H}=0.45$, and $\Delta x^{I-H}=0.54$, the per capita cost difference between plans.

If we only replace $q^{I}$ with $q^{H}$, then the value of $x^{I}$ changes to 0.50 , which accounts for $(0.99-0.50) /(0.99-0.45)=91$ percent of $\Delta x^{I-H}$. If we only replace $d^{I}$ with $d^{H}$, then the value of $x^{I}$ changes to 1.06 , which accounts for $(0.99-1.06) /(0.99-0.45)=-13$ percent of $\Delta x^{I-H}$. If we only replace $t^{I}$ with $t^{H}$, then the value of $x^{I}$ changes to 1.03 which accounts for $(0.99-1.03) /(0.99-0.45)=-7$ percent of $\Delta x^{I-H}$. If we only replace $r^{I}$ with $r^{H}$, then the value of $x^{I}$ changes to 0.79 , which accounts for $(0.99-0.79) /(0.99-0.45)=37$ percent of $\Delta x^{I-H}$. (If we standardize to fractions of cost differences accounted for by first-order effects, we find that incidence accounts for 84 percent of costs differences, demographic mix accounts for -12 percent, treatments account for -6 percent, and prices account for 37 percent.) Replacing two or more of the terms that compose $x^{I}$ with the corresponding terms from $x^{H}$ will produce the 11 interactions as listed in Appendix Table F. Note that the terms differ if we use $x^{H}$ as the base and substitute terms from $x^{I}$. 